\title{
Feasibility study on the construction of skyway in commercial center of typical extreme cold cities in
} China

Wanqing SU, School of Architecture, Harbin Institute of Technology; Key Laboratory of Cold Region Urban and Rural Human Settlement Environment Science and Technology, Ministry of Industry and Information Technology; China

Rui CHEN, School of Architecture, Harbin Institute of Technology; Key Laboratory of Cold Region Urban and Rural Human Settlement Environment Science and Technology, Ministry of Industry and Information Technology; China

Ziran ZHANG, School of Architecture, Harbin Institute of Technology; Key Laboratory of Cold Region Urban and Rural Human Settlement Environment Science and Technology, Ministry of Industry and Information Technology; China

Zhichong ZOU, Corresponding author, School of Architecture, Harbin Institute of Technology; Key Laboratory of Cold Region Urban and Rural Human Settlement Environment Science and Technology, Ministry of Industry and Information Technology; China

\begin{abstract}
Cold weather greatly reduces willingness and comfort of urban residents, especially in pedestrian experience and business vitality, which has brought negative impacts on cities in the extreme cold region. Urban construction in China has characterized with wide roads and huge blocks. One of the urgent problems in planning and construction of cold cities in China is how to build skyways with climate protection function in the central areas of typical extreme cold cities in China. This paper takes Minneapolis of the USA and Harbin of China as typical cases in the cold regions. Based on Arcgis10.4 platform, this paper analyzes open data such as OpenStreetMap and POI, and expounds the typical characteristics of the air corridor system construction from two aspects of the urban external space support and the land use support. In the aspect of the external space support of the city, the comparative analysis is carried out from three dimensions, namely, the macro, the meso and the micro scale, including the building density, the space between the building Street walls, the corridor length and the connection form. In the aspect of land use support, the paper makes a comparative analysis from the aspects of the functional relationship between blocks and the degree of land use mix. This study reveals the characteristics of the outer space and land use function suitable for the construction of skyway, and draws the suitability evaluation of the air corridor system construction in the eight commercial centers in Harbin, scopes the suitable area for the construction of the skyway, and determines the preliminary plan of the planning and construction. The purpose is to promote the pedestrian friendly and enhance the vitality of commercial center in extreme cold cities.
\end{abstract}

\section{Keywords}

Extreme cold city, Commercial center, Skyway, Urban external space, Land use mix degree 


\section{Introduction}

China is the most populous developing country with about 1.4 billion people and its land area ranks third in the world. According to architectural climate degree in China, the three northeastern provinces belong to the category of severe cold cities, about a tenth of the population living in cold areas. Severe weather in cold cities affects the quantities of pedestrians and the experience of walking (Madeleine, 2018). An effective way to reduce the adverse climate factors in winter is to directly isolate the impact of adverse factors on people, such as the climate-protected walking space generally established in urban commercial centers in Europe and the United States, that is, to create active outdoor spaces by building walking bridges and corridors, which can reduce the impact of adverse climates (such as rain, snow, wind, etc.) on human travel activities (Pressman, 1996). The downtown Minneapolis, Minnesota skyway network is the longest skyway net-work in North America. Such a network enables pedestrians to move more efficiently between connected buildings while avoiding weather and street traffic (Robertson, 1995; Corbett, 2009). The skyway is networks of above-grade connections between buildings that are often enclosed and climate controlled, and which link second-level corridors within buildings and various activity hubs, such as shops and offices (Robertson, 1993; Byers, 1998). The skyway was described as an indoor pedestrian system, or climate controlled walkway networks, indoor city or interior city (Maitland, 1992; Sijpkes, 1997; Montgomery, 1999). Throughout the growth and development of the system, the City of Minneapolis laid out several visions of a skyway system connecting most of the blocks downtown (Jacob, 1984; Kaufman, 1985). The skyway system has created a comfortable, safe, and interesting walking space, attracting the public to return and recovering the economy in the city center (Robertson, 1993). For cities under the background of severe cold climate, the skyway system has a very special significance, which plays a very important role in protecting the adverse climate, so it is highly respected by urban residents in cold region (Huang, 2011).

Similar to ordinary roads in terms of connecting destinations, the skyway network differs from other surface transportation networks in the following aspects. First, it is above and aligned with the street level, and only connects adjacent buildings. Second, it only allows pedestrian traffic. Third, although planned through the cooperation between private businesses and the city government, the skyway segments are privately financed and owned (Huang, 2013). In 1960, the Government of Minneapolis issued a ' draft plan ' on the rehabilitation of the central area, which refers to the idea of building a branch of urban three-dimensional transport vehicles (Minn, 1960). The construction of the air corridor system began in 1962, slowed down after 1992 and stopped in 2002 (Corbett, 2009). The skyway system remains the backbone of the mall's unique transit system and has played a significant role in enhancing the distinctiveness of downtown (Goldfield, 1976). The overall system changed from a local cluster to a tree and developed into a network, covering the whole city center. Skyway provides vertical separation of pedestrian and vehicular movements and, along with street-level sidewalks, represents a unified system of pedestrian facilities in the central business districts (Bhalla, 1985). The skyway system realizes the stratification of people and vehicles, which not only ensures the safety of pedestrians, but also avoids the interference of vehicle emission and avoids the influence of cold winter and hot summer climate. In addition, the skyway system can also create a dynamic walking environment, providing a favorable location for pedestrians to enjoy different views of the urban landscapes (Lynch, 1960). Skywalk systems contribute positively to the downtown transportation pattern in two important ways. First, they usually do a better job than do pedestrian malls of separating pedestrians from vehicular traffic. Second, skywalks can effectively link parking ramps on the periphery of downtown with the center, thereby encouraging suburban commuters to go directly from their cars to work without stepping foot on the street (Robertson, 1993). But the skyway system is in competition with the pedestrian system on the mall because the two are poorly integrated(Roberson, 1988).Access to the skyways and the proliferation of 
enclosed downtown shopping complexes, people choose to stay indoors during all seasons(Roberson, 1990).

Harbin, a typical cold city in China, had planned to build an air corridor system in the central area of the city, but it was not formed due to economic interests and safety management. Based on the research on the construction of skyway system in Minneapolis, this paper reveals the characteristics of urban external space and land use function suitable for the construction of skyway system, and draws the suitability evaluation of skyway system construction in eight commercial centers in Harbin, delimits the suitable area for the construction of skyway, and determines the preliminary plan of planning and construction, aiming to promote the winter walkability of cold cities in China and enhance the vitality of commercial centers.

\section{Methodology}

Based on Arcgis10.4 platform, this paper analyzes open data from OpenStreetMap and POI, and expounds the typical characteristics of the skyway system construction from two aspects of the urban external space support and the land use support. In the aspect of the external space support of the city, the comparative analysis is carried out from three dimensions, namely, the macro, the meso and the micro scale, including the building density, the space between the building Street walls, the corridor length and the connection form. In the aspect of land use support, the comparative analysis is carried out from three dimensions, namely, the macro, the meso and the micro scale, including function distribution, function link and function mix.

Minneapolis in the United States and Harbin in China are both typical cold cities, which are located near the $45^{\circ}$ north latitude. The winter is long, cold, dry, and the snowfall is large, which are represented in the world. The two cities have the same size and similar natural conditions, so they have high comparative research significance.

Due to the different urban development patterns in China and the United States, the forms of commercial centers are quite different. The city of Minneapolis is developing in groups and the boundary of commercial center is clear. The selected research area is the center area surrounded by urban expressway (Figure.1). Harbin has a history of more than 100 years. The early planning is influenced by western ideas. It has the characteristics of European city radiation and Chinese traditional city chessboard. However, in the past 70 years, after entering the stage of rapid urban development, the city presents the development model of wide roads and street areas. Therefore, the characteristics of Harbin commercial centers in different periods are different. The overall development of Harbin is circle-layer model. The

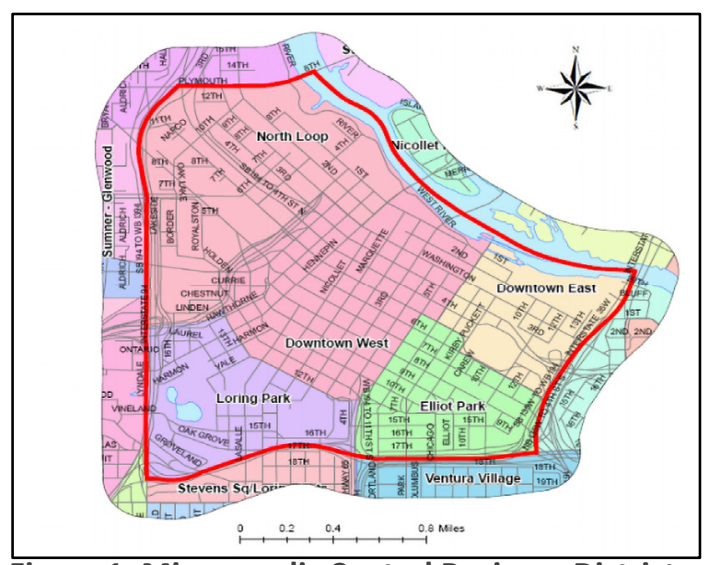

Figure 1. Minneapolis Central Business District Source : Minneapolis Planning Department

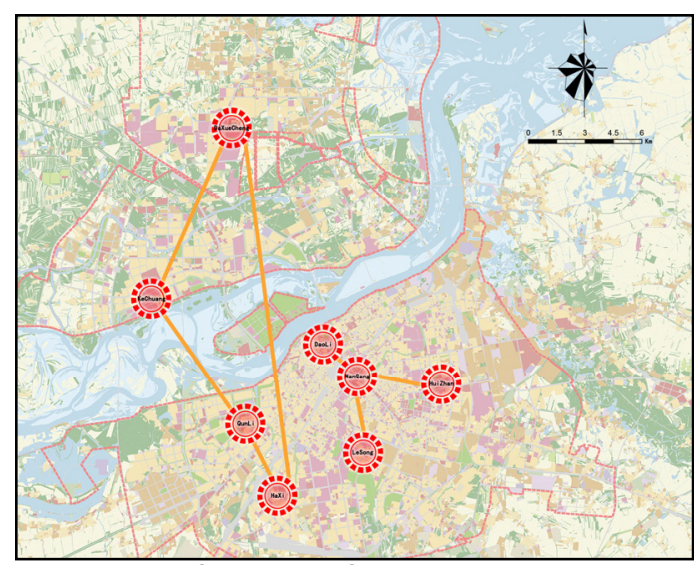

Figure 2. Harbin Central Business District

Source : Harbin Planning Department 
commercial centers are distributed in different regions, without obvious boundary characteristics. It is mixed with residential areas within a certain range, showing the characteristics of 'large number and small range '. Thus, this paper selects eight commercial centers in Harbin (Figure.2), four traditional old city commercial centers: Nangang, Daoli, Huizhan and Lesong. Four modern new town commercial centers : Haxi, Qunli, Kechuang and Daxuecheng.

\section{Results}

\subsection{Spatial analysis}

\section{1) Macro Scale__ The Building Density Characteristics}

By comparing the building density distribution of Minneapolis central business district with the connection of the skyway system connected block (Figure.3), it can be seen that the building density of the connected block is concentrated in the 0.5-0.7 range. It can be seen that the skyway system is connected to the high-density urban center area. The buildings in high density blocks are mostly functional composite buildings, and the mixture of multiple functions provides different services, which makes them closely linked in use and provides conditions for the construction of skyway system. Through the analysis of the distribution of building density in Minneapolis CBD, it is concluded that the location of the construction of the skyway system should be in the high-density blocks in the urban center, and the building density should be above 0.5 .

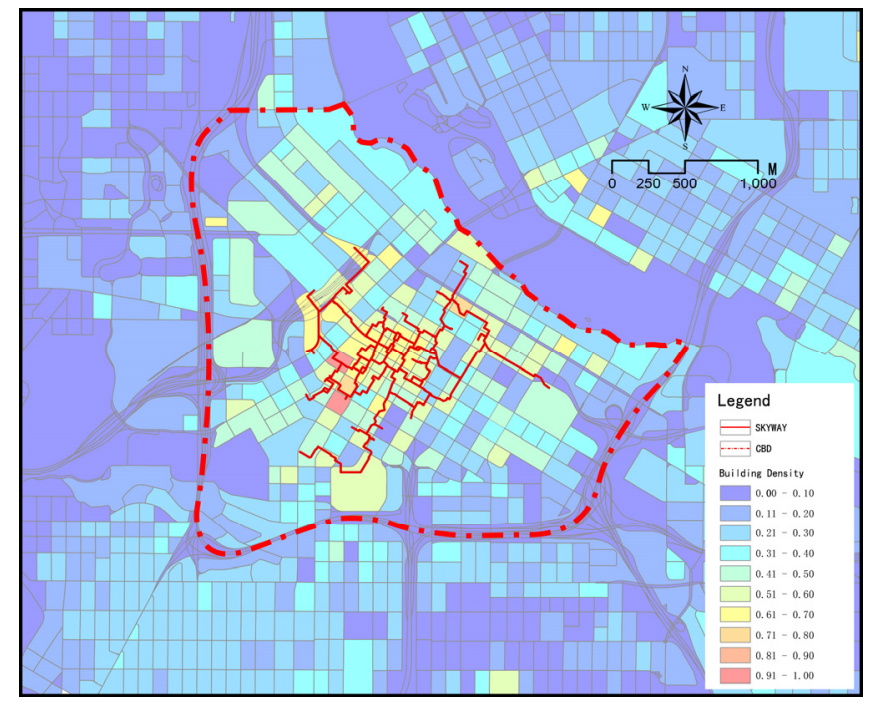

Figure 3. Building density distribution in Minneapolis CBD. Source: the authors.

In this study, the building density of eight commercial centers in Harbin was analyzed (Figure.4). It was found that the building density of Nangang, Daoli and Kechuang commercial centers was consistent with the building density characteristics of Minneapolis central business district. The building density of most blocks was concentrated in the range of $0.5-0.7$, which was consistent with the building density characteristics of the skyway system. Due to the mixed residential areas in other commercial centers, the building density is obviously insufficient to support the spatial characteristics of the skyway system, and the necessity of building the skyway is not high. 


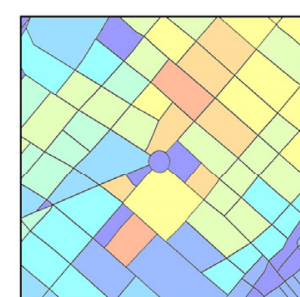

Nangang

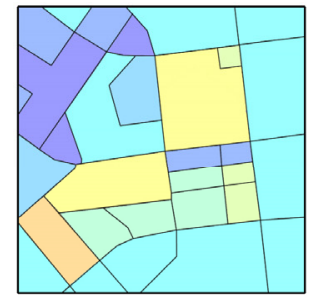

Haxi

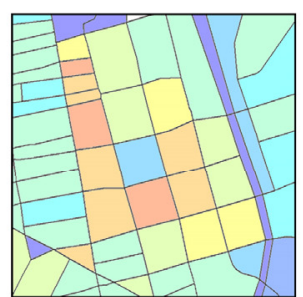

Daol i

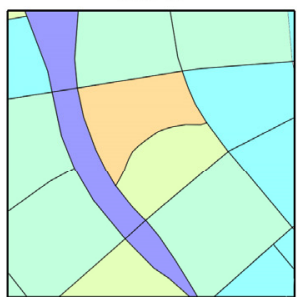

Qunli

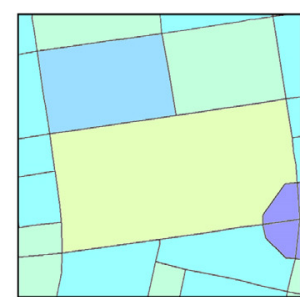

Huizhan

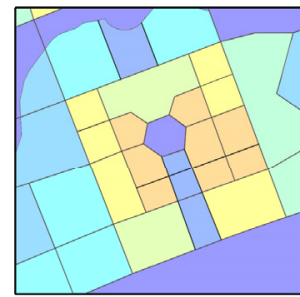

Kechuang

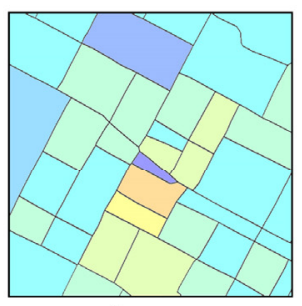

Lesong

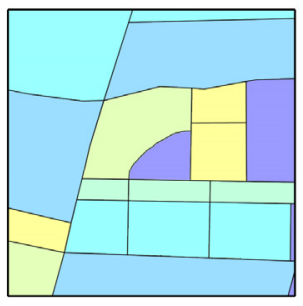

Daxuecheng

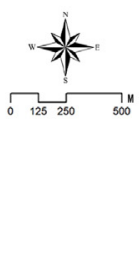

Figure 4. Building density distribution in Harbin commercial centers. Source: the authors.

2) Meso Scale__ The Width between the Building Street Walls and the Corridor Length

Through the analysis of the main street building interface width in the skyway system in Minneapolis (Figure.5), it is known that the street wall width of the skyway system is concentrated in $25-30 \mathrm{~m}$, and the block is ' small block, dense road network, narrow road '.

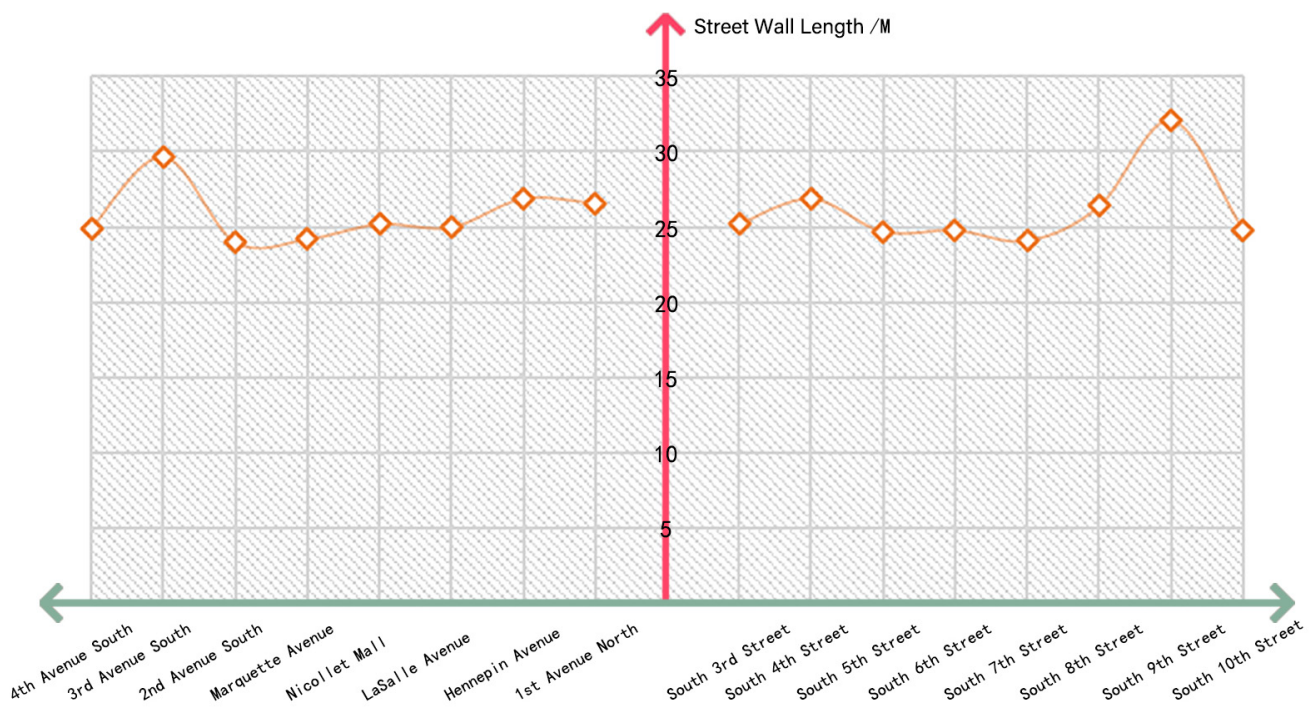

Figure 5. Width between the building street walls in Minneapolis CBD. Source: the authors.

At the same time, in the analysis of the corridor length (Figure.6), it is concluded that the length of the corridor is concentrated in the two length categories of ' $21-30 \mathrm{~m}$ ' and ' $31-40 \mathrm{~m}$ ', which is consistent with the characteristics of the block. Through the analysis of the block scale and corridor length of the syway system, it can be seen that the block construction of the skyway system should be compact in architectural layout, dense in block shape, and the distance between the street walls of the architectural world on both sides is about $30 \mathrm{~m}$. 

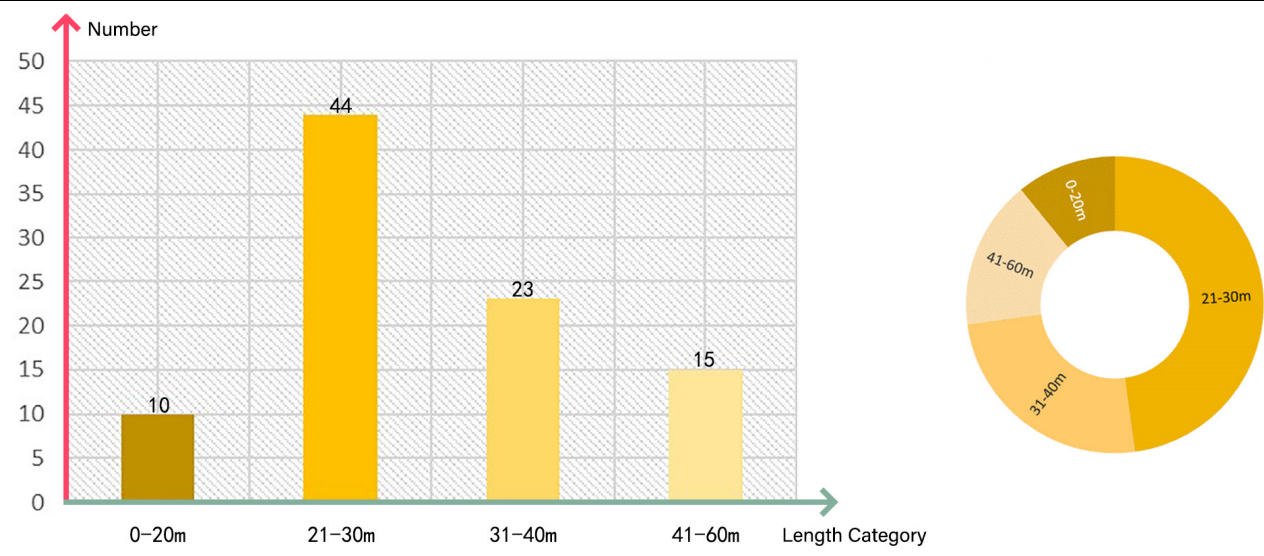

Figure 6. Length of the Corridor of skyway system. Source: the authors.

Through the comparative analysis of the street wall width of the main roads in the eight commercial centers in Harbin (Figure.7), it can be seen that the planning concepts are different due to the different planning and construction years. In the traditional commercial centers of the old city, the street wall width is approximately $30 \mathrm{~m}$, which is compliant with personal scale. In the commercial centers of the new city, most of the roads are the main roads of the city, showing the characteristics of wide roads. The street wall width is more than $50 \mathrm{~m}$, and the commerce is mostly large comprehensive shopping mall. People ' $s$ activities are concentrated in the interior. From the experience of Minneapolis CBD, it can be seen that the regional street wall width suitable for the construction of skyway is about $30 \mathrm{~m}$. Therefore, in the typical commercial center of Harbin, the feasibility of constructing skyway is high in Nangang and Daoli commercial center.
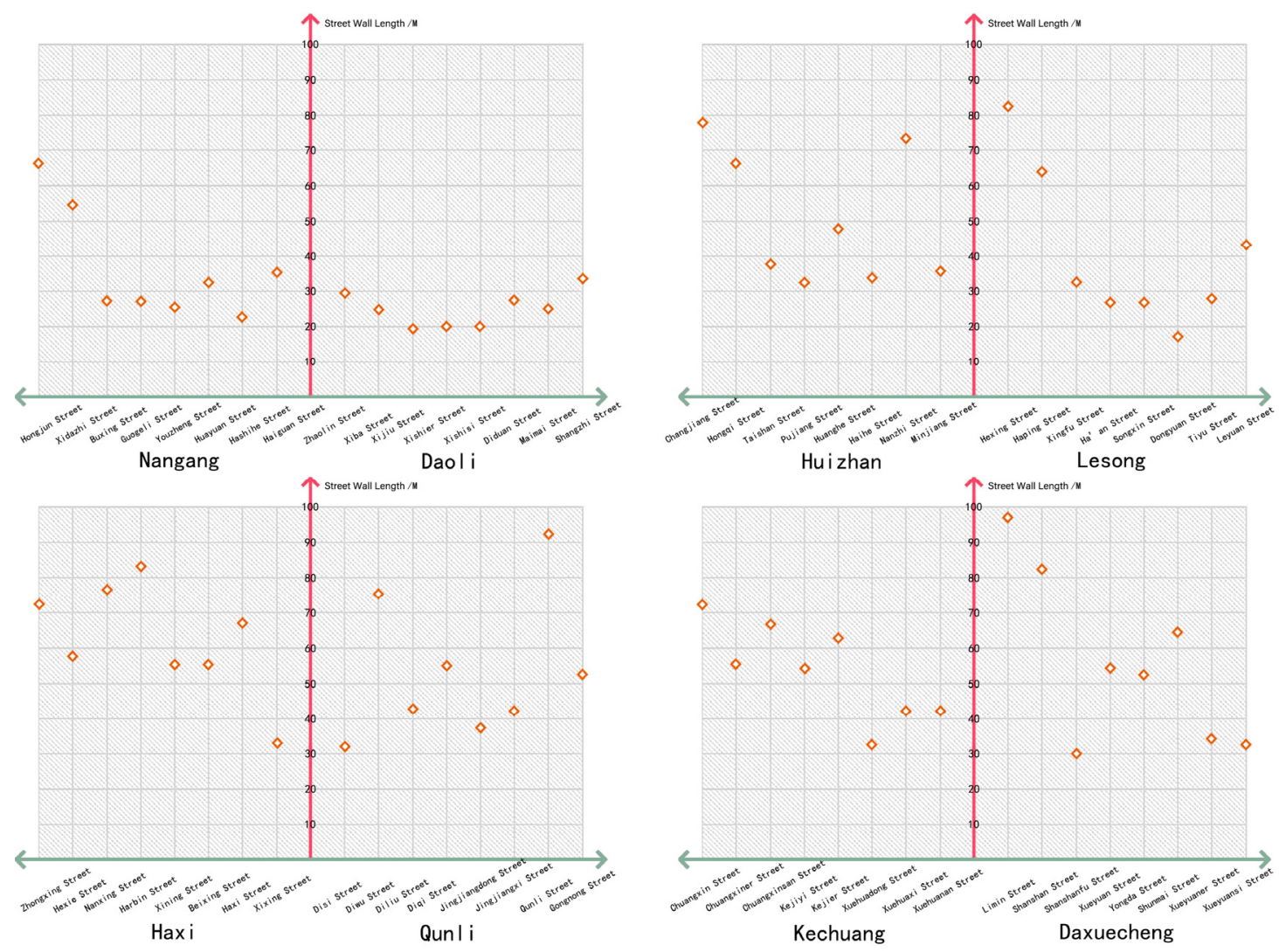

Figure 7. Width between the building street walls in Harbin commercial centers. Source: the authors.

3) Micro Scale_C_Connection between Buildings

Due to the construction era of the skyway system is large and not unified planning, there are different 
ways of connecting buildings. It is mainly manifested in three types: indirect type, external type and transit type. Indirect situations can be divided into two types: through and around. Indirect situation is mainly applicable to buildings with mixed commercial functions, and various functional connections are diverse. A complete walking path is formed through outdoor overpasses and corridors within the building. The external situation for building construction can't take into account the construction of skyway or building function affected by the external influence is not suitable for internal passage, but as an important node in the skyway system, can only choose to build corridor in the periphery of the building. The situation of transit mainly exists in the landscape architecture of park green space. These landscape buildings not only play the function of landscape rest, but also play the transfer station connecting the corridors of surrounding blocks, which is an important landscape node in the skyway system.

\subsection{Functional analysis}

\section{1) Macro Scale__Function Distribution}

Through the comparison between the zoning of Minneapolis and the connection of the blocks connected by the skyway system (Figure.8), it can be seen that the connected blocks are concentrated in the downtown area, including the central business area, the central service area and the central business area. The downtown area mainly includes business function, public service function, public management function and traffic function, which are embodied in retail business and service, food and drink service, entertainment and leisure, accommodation service, cultural and education service. The downtown districts are established to provide a range of retail, entertainment, office, employment, residential, institutional and governmental activities of citywide and regional significance. The regulations recognize the unique qualities of downtown as the business and cultural center of the region, as a community of high-density residential choices, and as a place where the combined environment attracts businesses, workers, shoppers, visitors, tourists, and residents.

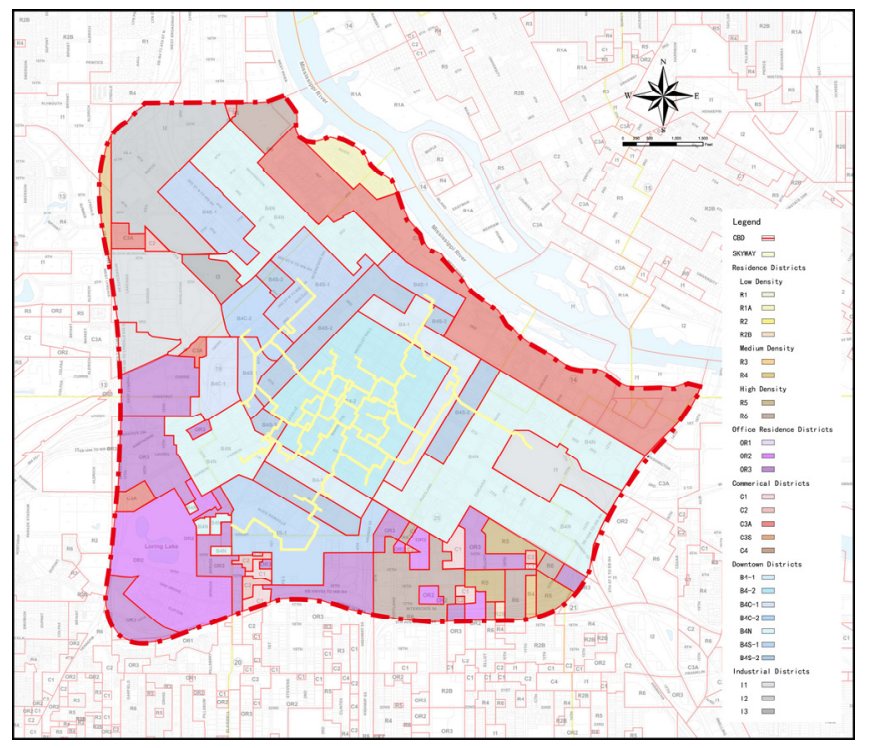

Figure 8. Function distribution in Minneapolis CBD. Source : Minneapolis Planning Department

Through the analysis of Minneapolis zoning, it can be seen that the area of the skyway system construction is the downtown area of urban commercial center. This area focuses on urban commerce, office, entertainment and other functions, which is the embodiment of urban commercial vitality and cultural vitality. Dense crowds and prosperous commerce support the skyway system. 
After comparing the overall planning land layout and current function of Harbin (Figure.9), the current land use distribution of eight typical commercial centers in Harbin is obtained. In general, the function of Harbin commercial centers is mixed, which is mainly mixed by commercial land public management land and residential land. The commercial land accounts for the main part of the commercial center, which is accord to the characteristics of the commercial center. However, there is no commercial center with a clear boundary and concentrated function in the city as a whole, resulting in the function of the commercial service industry being distributed in various groups of the city.

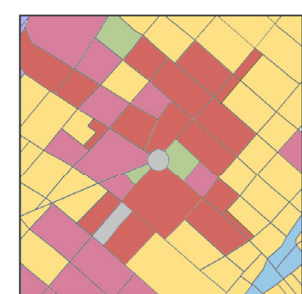

NanGang

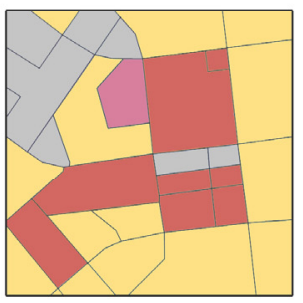

$\mathrm{HaXi}$

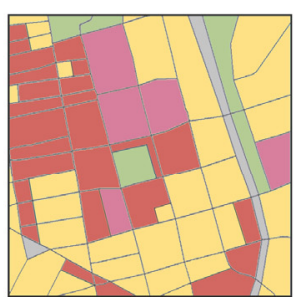

DaoLi

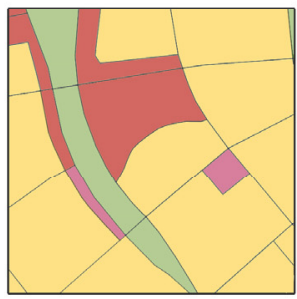

QunLi

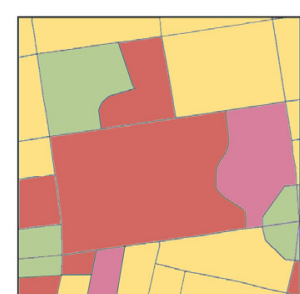

HuiZhan

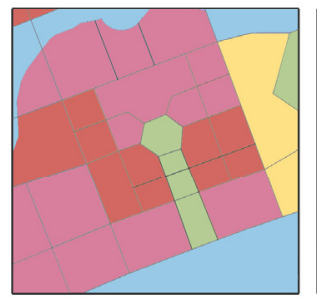

KeChuang

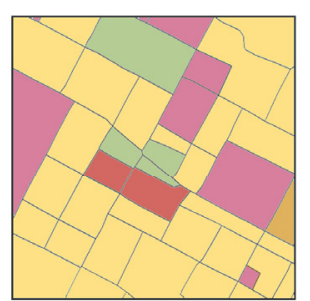

LeSong

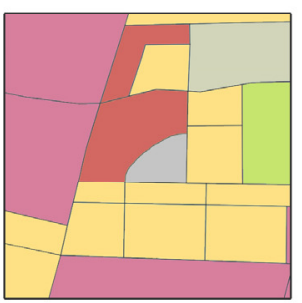

DaXueCheng

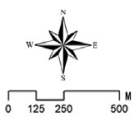

Figure 9.Function distribution in Harbin commercial centers. Source: the authors.

In eight typical commercial centers, Nangang and Daoli, as the commercial centers of the old city, have gathered the functions of commercial services. The building density and street wall width analyzed above also conform to the construction regularities of the skyway system in Minneapolis. Therefore, Nangang and Daoli can be discussed as key areas for the construction of the air corridor system.

\section{2) Meso Scale___Function Connection}

The functional buildings connected by the skyway system are mainly stadium, commerce, office, hotel, civic, apartment, parking, and green. It can be concluded that the above functions have the necessity and priority of building the skyway system. According to the statistics of the skyway connection function between adjacent plots, it is found that the commerce, office and hotel as the core function in the commercial center area should be preferentially connected, which accounts for the largest proportion. Secondly, stadium and parking, commerce and parking, exhibition and hotel should also be connected through the skyway system.

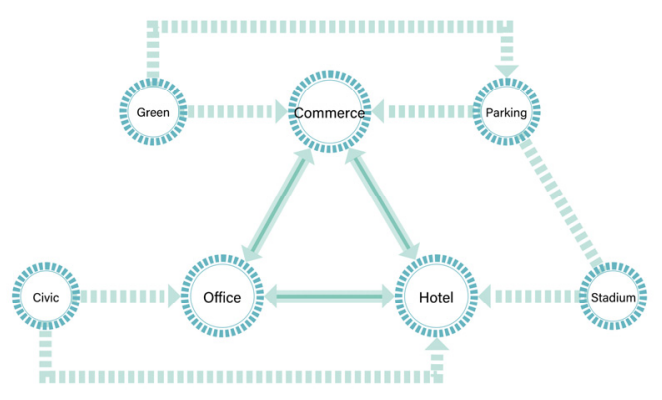

Figure 10. Function connection diagram.

Source: the authors.
Through the analysis of the function buildings of the skyway system connection in the Minneapolis CBD, it is concluded that the priority of its functional connection (Figure.10) should be considered in the construction, that is commerce, office, and hotel should be interconnected, and in large public buildings such as stadium should be considered connected with parking, and commerce should also be connected with parking through corridors. After the skyway system forms a certain scale, it can be considered to connect the park with parking, civic 
and office, stadium and hotel, and other functions.

3) Micro Scale___Function Mix

According to the classification of POI in Gaode Open Platform, there are six categories which have strong correlation with the commercial center, catering services, shopping services, living services, accommodation services, science services, and financial insurance services. In this study, the function mixing degree of Nangang and Daoli is carried out, and the buildings with high commercial vitality are evaluated, and the feasibility analysis is carried out.

Nangang commercial center, the traditional city commercial center, has been the center of the municipal business circle. In the Nangang commercial center, several comprehensive commercial buildings meet the functional requirements of skyway system construction, which are concentrated on the northwest side of Xidazhi Street, namely Zhengda Mall, Yuanda Mall, and Qiulin Mall, etc. (Figure.11). Due to the commercial prosperity of the above commercial buildings, the feasibility of building skyway is high, and the crowd is dense, the necessity of building skyway is also high. Because the connection is a comprehensive commercial building, the skyway should be connected with the original corridor channel inside the building to form an internal surrounded skyway system, which can provide more street stores. The stores on both sides of the channel also provide pedestrian interest to attract pedestrians.

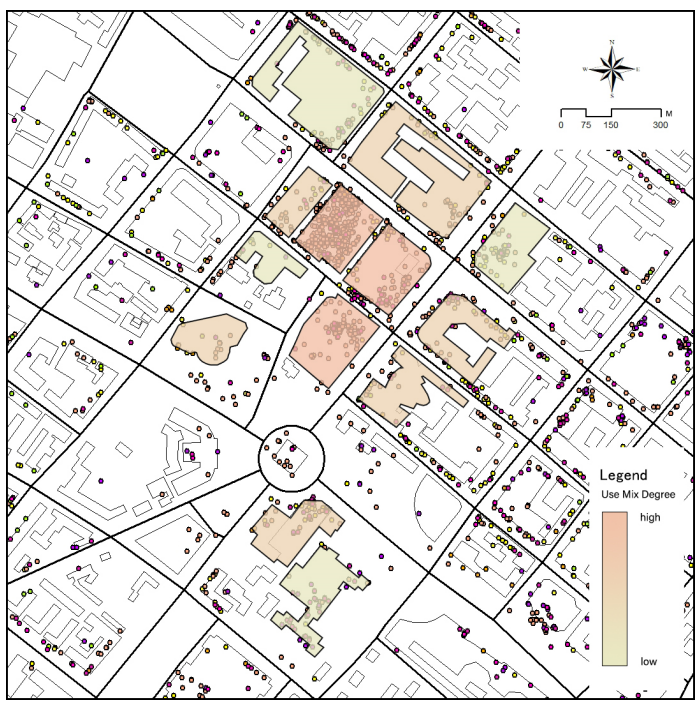

Figure 11. Functional Mix Analysis in Nangang

Commercial Center

Source: the authors.

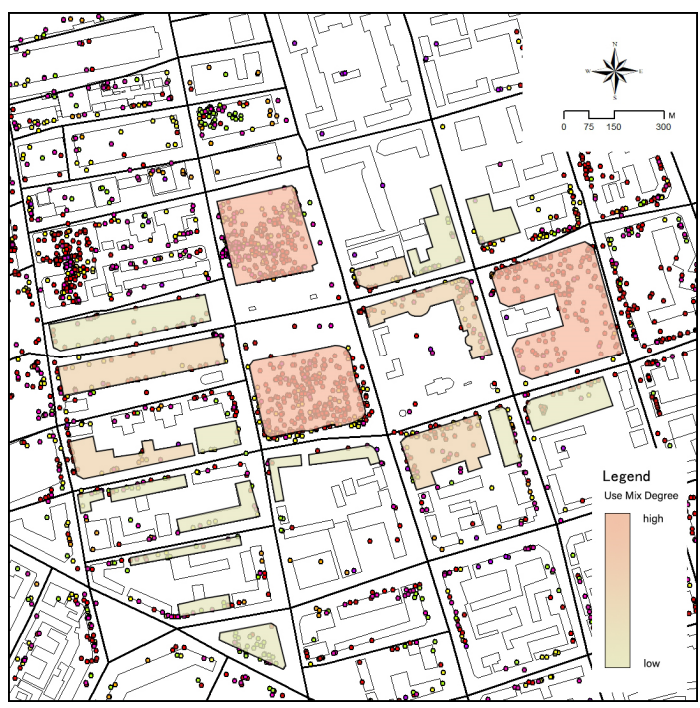

Figure 12. Functional Mix Analysis in Daoli

Commercial Center

Source: the authors.

Daoli commercial center is a regional commercial center, which is developed by tourist attractions and local business needs. In Daoli commercial center, it has the typical spatial characteristics of ' small block, dense road network '. The contradiction between people and vehicles in transportation system is prominent, and the necessity of building skyway system is high. Around the church of Saint Sophia, there are many comprehensive commercial buildings and hotel buildings, such as McCaylor Mall, Toulong Mall, and Home Hotel. With high commercial vitality and high functional connection, it is suitable to connect into a complete walking system, and the feasibility of building skyway is high (Figure.12). In commercial buildings, it is suitable to select the internal surround type, which is connected with the internal corridor of commercial buildings, but in hotel buildings, the external form should be taken to reduce the interference to the hotel. Consideration should also be given to creating a transparent interface for urban landscapes so that pedestrians walking in the skyway system can appreciate landmarks and be more identifiable. 


\section{Conclusion}

The successful experience of Minneapolis skyway system proves that the closed walking system with climate protection characteristics is of positive significance for ensuring pedestrian walking comfort in winter, improving business vitality and solving the contradiction between people and vehicles in the traffic of commercial centers. Through the analysis of spatial support and functional support of Minneapolis skyway system, the construction characteristics and regularities are obtained. According to the condition of Harbin city, the comparative analysis shows that Nangang and Daoli in the old city commercial centers conform to the regularities of constructing skyway. The preliminary scheme is as follow (Figure.13).

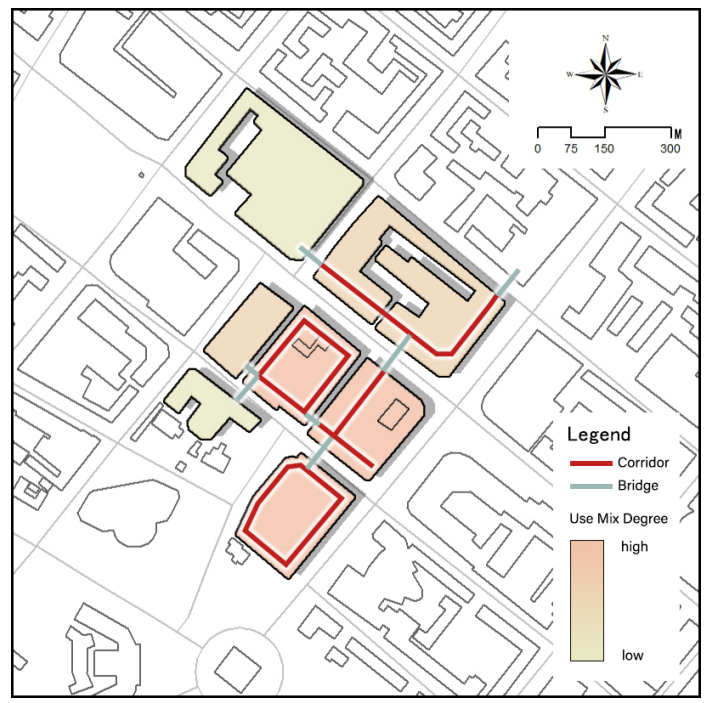

(a)Nangang commercial center

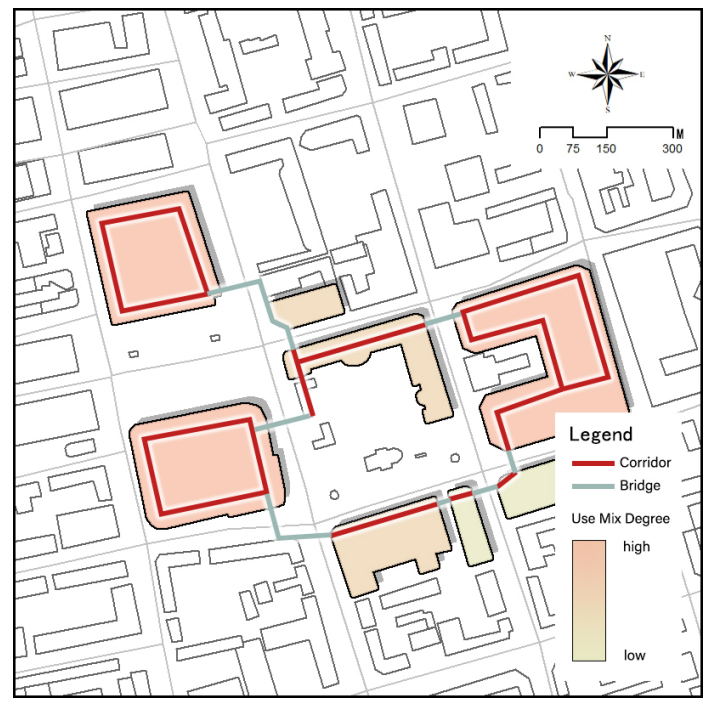

(b)Daoli commercial center

Figure 13. Preliminary scheme of skyway in Harbin commercial center. Source: the authors.

Due to the scattered distribution of Harbin city commercial centers in residential areas, the construction of skyway focuses on the connection between several blocks, and fails to form a large-scale system. However, under this condition, it can form a circular walking system, which can provide climate protection for pedestrians in severe weather. At the same time, it can effectively resolve traffic congestion in commercial centers. Through the comparative study of eight commercial centers in Harbin, a typical cold city in China, including four traditional commercial centers and four new city commercial centers, the construction strategy suitable for climate protection in cold regions of China is obtained.

Through the analysis of Minneapolis skyway system and the feasibility of skyway in Harbin commercial centers, the construction regularities of skyway can be obtained, that is, the building density in the urban commercial center is more than 0.5 , and the width between the building street walls is approximately 30 meters. In addition, different connection methods should be selected according to the different functions of the building. The feasibility of skyway construction is high in dynamic commercial buildings with high functional mixing.

\section{Funding}

This work was jointly Supported by the Fundamental Research Funds for the Central Universities (Grant No. HIT.HSS.202108) and (Grant No. AUEA5750000120), the Graduate Education and Teaching Reform Project of Harbin Institute of Technology (21HX0303) . 


\section{References}

Jacob, B., and Morphew, C. (1984). Skyway Typology: A Study of the Minneapolis Skyways. Washington, DC: AIA Press,

Kaufman, S. H. (1985). The Skyway Cities. CSPI, Minneapolis, MN

Lynch, K. (1960). The image of the city (Vol. 11). Massachusetts: MIT press.

Robertson K A. (1994) Pedestrian Malls and Skywalks: Traffic Separation Strategies in American Downtowns[M]. London: Avebury Press.

Bhalla, M. K., and Pant, P. D. (1985). 'Pedestrian traffic on Cincinnati skywalk system'. Journal of transportation engineering, 111(2), pp.95-104.

Byers, J. P. (1998). 'Breaking the ground plane: The evolution of grade-separated cities in North America'. Minnesota: University of Minnesota.

Corbett, M. J., Xie, F., and Levinson, D. (2009). 'Evolution of the second-story city: the Minneapolis Skyway System'. Environment and Planning B: Planning and Design, 36(4), pp.711-724.

Goldfield, D. R. (1976). 'A Reply To Professors Zikmund and Hadden'. Urban Affairs Quarterly, 12(1), pp.112-116.

Huang, A., and Levinson, D. M. (2011). 'Modeling Minneapolis Skyway System', Transportation Research Board 90th Annual Meeting (No. 11-0424).

Huang, A., and Levinson, D. (2013). 'The structure and evolution of a skyway network'. The European Physical Journal Special Topics, 215(1), pp.123-134.

Maitland, B. (1992). 'Hidden cities: The irresistible rise of the North American interior city'. Cities, 9(3), pp.162-169.

Minneapolis (Minn.). City Planning Commission. (1960). Possible alternatives: central area zoning districts. [Minneapolis, Minn.]: City of Minneapolis Planning Commission.

Montgomery, M. R., and Bean, R. (1999). 'Market failure, government failure, and the private supply of public goods: The case of climate-controlled walkway networks'. Public Choice, 99(3), pp.403-437.

Pressman, N. E. (1996). 'Sustainable winter cities: Future directions for planning, policy and design'. Atmospheric environment, 30(3), pp.521-529.

Robertson, K. A. (1988). 'Pedestrian skywalk systems: downtown's great hope or pathways to ruin?'. Transportation quarterly,'42(3). pp.457-484

Robertson, K. A. (1990). 'The status of the pedestrian mall in American downtowns'. Urban Affairs Quarterly, 26(2), pp.250-273.

Robertson, K. A. (1993). 'Pedestrianization strategies for downtown planners: Skywalks versus pedestrian malls'. Journal of the American Planning Association, 59(3), pp.361-370.

Robertson, K. A. (1995). 'Downtown redevelopment strategies in the United States: An end-of-thecentury assessment'. Journal of the American Planning Association, 61(4), pp.429-437.

Sijpkes, P., and Brown, D. (1997). 'Montreal's indoor city-35 years of development'. In 7th International Conference on Underground Space, pp.15.

Stout, M., Collins, D., Stadler, S. L., Soans, R., Sanborn, E., and Summers, R. J. (2018). “Celebrated, not just endured:" Rethinking Winter Cities. Geography Compass, 12(8), pp.e12379. 